Neth. J. PI. Path. 99 (1993) Supplement 3: 161-171

\title{
Systems approaches in epidemiology and plant disease management
}

\section{R. RABBINGE, W.A.H. ROSSING and W. VAN DER WERF}

Department of Theoretical Production Ecology, Wageningen Agricultural University, P.O. Box 430, $6700 \mathrm{AK}$ Wageningen, the Netherlands

Accepted 28 October 1993

\begin{abstract}
This contribution to Zadoks' liber amicorum reviews the developments in quantitative epidemiology during the last decades. It elucidates the progress in this field and shows how empirical crop protection with many phenomenological aspects transformed into a science-based (inter)discipline.

The availability of experimental tools and the rapid development and introduction of computers enabled the application of systems approaches which stimulated a revolution in thinking and caused a considerable improvement of strategic and tactical decision making in crop protection. Zadoks played a crucial role in that development.
\end{abstract}

Additional ke'words: simulation, modelling, crop protection

\section{Introduction}

Zadoks' contribution to epidemiology' and plant disease management

From the time of his arrival in Wageningen in 1956, Zadoks contributed to the systems approach in crop protection. As a fresh scientific worker in crop protection, he was aware of the necessity to determine fundamental epidemiological parameters such as infectious period, latency period and spore production under well-defined conditions, to better understand epidemiology of plant pathogenic fungi under field situations. When he started as a professor at the university, he received a so-called bride's contribution of one million Dutch guilders, an unbelievable amount nowadays, to construct climate cabinets and climate rooms that allowed him to undertake these studies. Zadoks' studies of fundamental epidemiological parameters laid the basis for his quantitative understanding of stripe rust epidemics in the field.

Systems approaches 'avant la lettre' were the corner stones of Zadoks' work at the Wageningen Agricultural University. He is well-known for his scientific work on stripe rust epidemiology, tropical plant diseases, systems analysis of plant disease epidemiology, spatial spread of plant diseases, quantification of damage and resistance, and last but not least, his invaluable work on plant disease management. Zadoks published over 300 scientific and popular scientific papers, some of them scientific mile-stones, e.g. on the unravelling of the relative importance of basic epidemiological parameters (Zadoks, 1971). The textbook Epidemiology and plant disease management, written together with Richard D. Schein (Zadoks and Schein, 1979), is appreciated by students for its clarity and is widely quoted (Fuchs, 1989). In his lectures, Zadoks is valued for his systematic approach, precise formulation and lucid explanations, the careful use of dimensions in 
equations, the engaging story-telling and his broad knowledge on historical, social and economic issues (Zadoks, 1988, 1991). All this demonstrates how an academic career can flourish at an agricultural university. As a researcher he managed to combine theoretical work, for instance on the spatial spread of disease (Van den Bosch et al., 1988a,b, 1989), with applied subjects, such as the computer-based warning system for cereal diseases, EPIPRE (Zadoks et al., 1984). Not only his scientific contribution deserves mentioning, but also the role as a university governor and scientific ambassador.

The introduction of new methods, new paradigms and new approaches characterize Zadoks' career as an epidemiologist. Some aspects of his contribution to the application of systems approaches to the understanding and management of plant diseases will be elaborated in this paper.

\section{Systems, models and systems approaches}

In the following, various concepts are used. To prevent misunderstanding, all concepts are explicitly defined. A system is defined as a limited part of reality with related elements that act more strongly on each other than they act on the cnviromment (Leffelaar, 1993). The environment acts on the system. A system that evolves in time is a dynamical system. A dynamical system is characterized by state variables, rulcs detcrmining the rates of change of those states in time and space, the state of the system at time 0 and boundary conditions, i.e. the state of the system at the spatial 'edge'. A pathosystem is defined as a system of a host species and a parasite species, influencing each other at several integration levels and affecting each others population dynamics, genetics and evolution (Zadoks and Schein, 1979).

Modelling comprises the construction of simplified representations, 'models', of systems and the study of their behaviour. Modelling involves several steps. In the analysis phase, a system is 'taken apart' to analyze and describe the component subsystems or processes in terms of quantitative relationships. In the integration phase, the subsystems models are collated to construct a quantitative model of the whole system. Behaviour of the system model is compared with observations on the system to validate or invalidate the model. Models that are constructed along these lines act as a bridge between integration levels and are of great help in understanding systems and locating gaps in the knowledge about the system. Such mechanistic or hierarchical models have explanatory value as their parameters have clear biological meaning and can be measured at process level. Descriptive models do not span various integration or hicrarchical levels. They are mimics of the real system and their parameters characterize processes on the system level, rather than on the process level beneath it. In epidemiology, for instance, a descriptive model can be based on the relative rate of growth of a diseas: population, which is an aggregate parameter, whereas a mechanistic, hierarchical model would be based on quantification of such processes as reproduction and survival, which depend on abiotic environmental factors, biotic interactions and spatial phenomena. Descriptive models are in most cases empirical and of a statistical nature. They are based on observations of the functioning of systems. Correlations between the variable at systems level and some abiotic variables are used in these models. For example the relation between $r$, the relative growth rate of an epidemic and environmental factors such as temperature and leaf wetness period:

$$
r=a T+b L+c T L+d
$$

in which $T$ is temperature, $L$ is leaf wetness period and $T L$ the product of the two. $a, b, c$, and $d$ are regression coefficients. In statistical terms, the variable $r$ is the dependent 
variable, while the independent variables $T$ and $L$ explain the variation in $r$. This is not an explanation in causal terms. That would require understanding and quantification of the basic processes that determine the behaviour at the system level.

Mechanistic models are often inadequate in practical disease management because they require detailed information on the state of the system and its environment, for instance frequent measurements of wind speed and direction to calculate spore dispersal, or duration of leaf wetness at different heights in the canopy to calculate infection efficiency. Such detailed information is scldom available. Descriptive models, on the other hand, are often inadequate in research because they oversimplify the real situation. They therefore do not appeal to the biologist. In epidemiology and plant disease management, the development of mechanistic and descriptive models goes hand in hand. When the timebehaviour of a dynamic model can be derived by analytical integration methods, the model is called an analytical model. Analytical models are often descriptive because biological details hamper mathematical analysis. The analysis of epidemiological models that contain just the barebones of realism involves already difficult mathematics (Van den Bosch et al., 1988a,b, 1989). In most situations, mathematical analysis is not possible. Then, numerical methods are used to calculate the evolution of the system over time. Any numerically solved model is often called a simulation model, even if it is a descriptive model.

In this paper the terminology used is based on Rabbinge and De Wit (1989). Simulation is then defined as the construction of a model (a simplified representation of reality) and the study of the behaviour of the model in comparison with that of the real system. Thus in an iterative way insight in the behaviour of the system and an explanation on basis of the underlying physical, chemical and physiological processes is possible.

A systems approach as applied to crop protection is defined as a methodology of the analysis of a pathosystem or the design of a plant disease management system that is based on a hierarchical approach in which quantitative models play a central role. Systems approaches can occur on many integration levels, from the leaf to the continent (see below). Prediction is the act of making quantitative statements, expected value \pm standard error, about the future state of a system.

\section{Plant disease management at different integration levels}

\section{Integration levels}

Zadoks and Schein (1979) define plant disease management as the total of all actions, intentional or not, that serve to regulate disease levels so that they remain below the economic threshold level. The definition covers disease management activities at all scales of complexity relevant to epidemiology. These scales run from the organismal to the continental level. Associated with each scale of complexity are typical scales of time and space. At the organismal level, pathosystem management concerns disease-crop interactions during the growing season of a single crop with time coefficients typically of hours. The time coefficient of a process is defined as the reciprocal of the relative rate of change (Leffelaar, 1993). For example an increase of $5 \%$ per year results in:

$$
\{\text { time coefficient }\}=\{\text { relative rate of change }\}^{-1}=\frac{1}{0.05 \text { year }^{-1}}=20 \text { year }
$$

At the continental level, quarantine measures pertain to a supra-national scale with typical 
time coefficients of years. To understand phenomena at a particular scale of complexity, information is needed on the dynamics of processes at the next lower level of integration. Processes at different integration levels have time coefficients that typically differ by two orders of magnitude, i.e. a factor 100 . Simulation models bridge two or maximally three levels of integration and are used as instruments of synthesis. They allow quantitative evaluation of hypotheses. Thus, a systems approach involves repetitious scaling down - or analysis - and scaling up - or synthesis - to arrive at understanding the functioning of systems. Usually, lack of knowledge and large differences in temporal and spatial scales prohibit bridging of more than two adjacent scales of complexity. Thus, plant-host interactions at the molecular level are seldom represented in epidemiological and crop growth models. Problems of aggregation are also encountered when research results at the crop level need to be scaled up to the cropping system level.

Disease management can be classified according to its temporal and spatial scales as policy-oriented, strategic, actical or operational (Conway, 1984). Policy-oriented disease management concerns actions at the regional, national, or supra-national level, aimed at developments over several years at least. Examples include the national expenditure on crop protection in the Netherlands, which was analyzed by Zadoks (1984), and the pesticide requirement of agriculture in Europe under various objectives with respect to productivity and environment (Netherlands Scientific Council for Government Policy, 1992). Knowledge of various production technifues including crop protection is necessary in such studies.

Strategic, tactical and operational disease management problems differ in temporal scale, but may apply to the same spatial scale (Fig. 1). Strategic management problems at the field level concern decisions involving several growing seasons, while tactical management problems concern decisions within one growing season. Alternative strategies of disease management at the farm level differing in economic and ecological objectives were evaluated by Rabbinge and Zadoks (1989). The same authors contributed to tactical

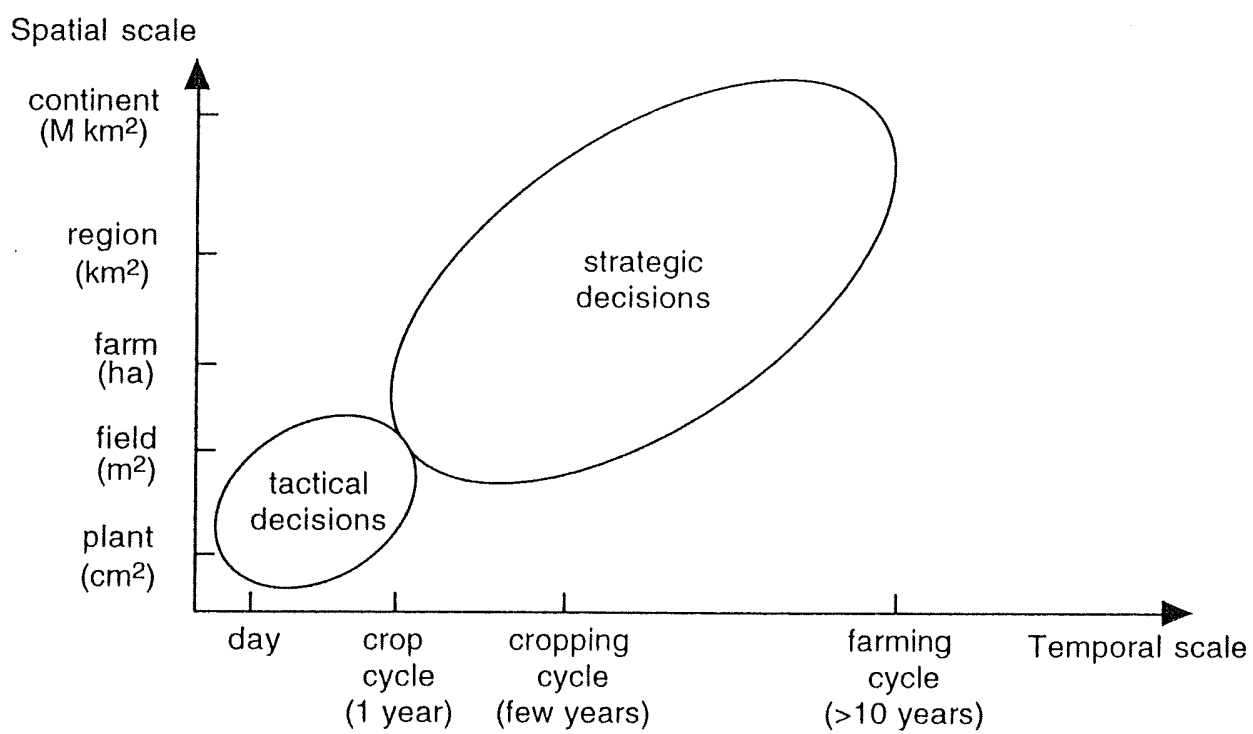

Fig. 1. Spatio-temporal characterization of decision problems in crop protection. The area of each class is a measure of the decision alternatives available. 
disease management through the computer-based advisory system for chemical control of aphids and plant diseases in winter wheat, EPIPRE (Zadoks et al., 1984). Operational management addresses the 'how-to' question and concerns the day to day implementation of decisions made at the tactical and strategic levels, for example the choice of equipment to carry out mechanical weeding. Optimization of operational management, typically an engineering problem, is not elaborated here. Thus, a hierarchy of disease management categories exists in which, proceeding from policy-oriented to operational management, the temporal scale as well as the range of possible decisions decreases.

\section{Tactical disease management}

Tactical plant disease management systems deal with four interacting entities: the plant host as victim and food source, the pathogen as unwanted consumer, the environment (biotic and abiotic) as the always changing background to the scene, and man as process controller and intended consumer. The disease tetrahedron (according to Zadoks and Schein, 1979) represents the interactions (Fig. 2). Irrespective of their spatial scale, sound systems of tactical disease management comprise four building blocks: sampling methods, epidemiological relations (Fig. 2A), damage relations (Fig. 2B), and cost/ benefit/ risk analyses (Fig. 2C).
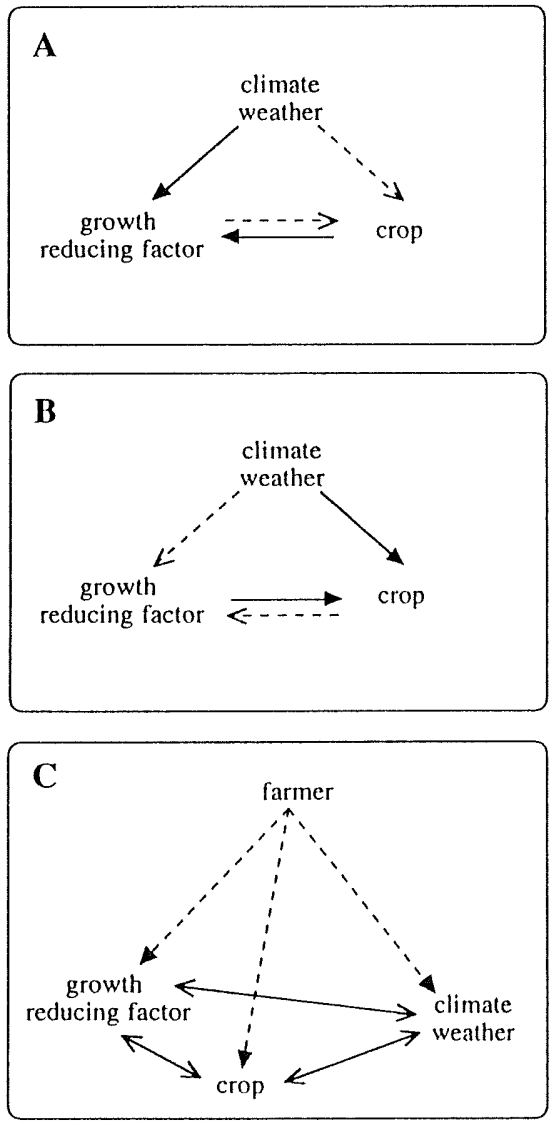

Neth. J. Pl. Path. 99 (1993) Suppl. 3
Fig. 2. Disease triangle or tetrahedron with emphasis on (A) population dynamics of the growth reducing factor, (B) injury and damage, and (C) crop protection. Solid lines represent emphasized relations. 
Sampling methods. Sampling methods represent the instruments with which the decision-maker keeps track of the state of the system. Usually, the state of the system is characterized by the intensity of the disease and the status of the substrate, i.e. the crop or the harvested product. Statistical theory and biological expertise and ingenuity has been combined to arrive at sampling protocols which are at the same time simple, of a sound biological basis, labour extensive, compatible with other crop management activities, and cheap relative to the value of the product (Rabbinge and Mantel, 1981). Nyrop and Van der Werf (1993) propose a monitoring procedure in which not only sample size but also time interval between sampling dates is optimized. In the EPIPRE system, the sampling interval depends on crop age, disease severity and its rate of change. Sample size and sampling time are not optimized jointly in an explicit fashion, but rules of thumb are used to guarantee accuracy and to limit sampling effort. Sample size, the number of tillers or leaves to be inspected, was chosen such that an acceptable coefficient of variation would be attained at densities close to the damage threshold. To minimize sampling effort absence/presence sampling methods were developed.

Epidemiology. Knowledge of the current state of the system can be used to make projections into the future of the evolution of the state, provided sufficient epidemiological knowledge, combined with knowledge of damage relations is available. Simulation models are well-suited to show the extent to which the dynamics of a pathosystem is understood, thus providing guidelines for forecasting. For example, quantitative models of the epidemiology of the wheat diseases Septoria tritici, Erysiphe graminis, and Puccinia recondita showed that far fewer lesions developed in field experiments than was predicted, using life-table data (unpublished MSc theses, Dept. of Theoretical Production Ecology, Wageningen Agricultural University, the Netherlands). Moreover, the discrepancy between simulated and observed disease progress appeared to vary per field. Sensitivity analyses of the epidemiological models showed that small changes in the time of onset of the epidemic, in initial inoculum density and in parameter values could lead to major changes in disease progress as a consequence of positive feedback between lesion density and rate of increase. Apparently, field specific factors affecting spore production, spore dispersal and host penetration were insufficiently understood or not quantified accurately enough. Therefore, for forecasts in EPIPRE, simple exponential models were used which were calibrated on field data using regression analysis. Forecasts are updated using the sampling information on disease incidence by the farmer. In this way, field-specific prediction errors were kept in check. This updating procedure is known in operations research as decision-making with rolling planning horizon (Hendriks and Van Beek, 1991).

Another example concerns cereal aphids. The major species in Western Europe are Sitobion avenae and Metopolophium dirhodum, while Rhopalosiphum padi is of local importance as vector of barley yellow dwarf virus. Mechanistic models were used to understand the typical pattern of population increase and decline. After immigration into a wheat field, aphid densities increase and reach a peak at crop development stages midto-late milky ripe (Decimal Code 75 to 77 ; Zadoks et al., 1974). In studies at the level of individual aphids, the relations between development rates of various instars and temperature were determined. With advancing crop development stage and decreasing host plant quality, fecundity decreases and the fraction of winged offspring increases (Rabbinge et al., 1979; Carter et al., 1982). Synthesizing this information at the population level using stage-structured models showed that high temperatures result in lower peak densities than low temperatures because temperature has a relatively greater effect on the rate of crop development than on the rate of population incrase. Hence increasing temperature shor- 
tens the period of population increase more than it augments the rate of increase. The modelling studies also showed that effects of parasitoids and predators vary greatly between locations and years, depending on initial conditions, weather and presence or absence of hyperparasitoids. Unfortunately, monitoring of parasitoid and predator densities is not practical due to the large sample sizes required. As an alternative approach, Entwistle and Dixon (1986) and Nyrop and Van der Werf (1993) advocate the use of sampling techniques that monitor the rate of change and dynamics of the pest population without taking explicit natural enemy samples. Calculations of expected pest population dynamics are based on those samples to assess biological control. This circumvents the problems of monitoring natural enemy complexes and the sometimes great sensitivity of the dynamics of predator-prey systems to initial conditions, which makes biological control inherently difficult to predict. Monitoring natural enemy complexes may become practically feasible in the future if more insight has been gained into which natural enemy groups are important at which times. Such knowledge is presently inadequate, although research is going on to improve upon this situation (Mols, 1993; Van den Berg, 1993).

Damage relations. Traditionally, relations between pest and disease intensity and damage were of an empirical rather than a causal nature. Systems approaches have been extremely valuable in gaining more understanding of the interactions at the whole-plant level which result in damage at the crop level. Mechanistic models of crop growth simulate crop growth on the basis of knowledge on light interception, assimilate production, respiration, assimilate distribution to various organs and biomass formation. These processes at the whole-plant level may be used to investigate the way a growth-reducing factor may decrease crop growth and yicld. Studies of damage relations from a systems point of view, therefore, include experimental work to quantify effects of different pest intensities on whole-plant processes. In EPIPRE, damage relations derived from a wheat growth model into which uptake of assimilates by aphids and decreased leaf photosynthesis by honeydew was introduced, were as accurate as empirical damage relations derived from 15 years of ficld data on more than 20 locations (Rossing, 1991). Due to the mechanistic nature of the model and the inclusion of the effect of nitrogen shortage on growth and development, assessments of damage at lower attainable levels of crop production could be made. Similar studies have been carried out for other growth reducing factors, e.g. weeds (Kroplf and Van Laar, 1993).

Cost/benefit/risk analyses. Different management tactics result in different costs due to damage and control, and different levels of uncertainty about these costs. Selection of the best tactics requires criteria to decide the extent to which the objectives of the ultimate user are satisfied. Thus, the system includes the decision-maker's subjective preferences, especially with regard to risk. Commonly tactical disease-management systems assume risk-averseness and tune the management recommendations accordingly. Alternatively, the riskiness of alternative lactics may be presented, leaving the choice of the best tactics to the decision-maker (Rossing et al., 1993).

\section{Strategic disease management}

While tactical management actions are taken during the season in response to what happens to the crop, strategic management actions are those actions that are taken before the crop is in the field, e.g. the choice of a crop rotation scheme. The time scale of these decisions is years.

The DFS (Development of Farming Systems) experiment is one of the few examples

Neth. J. Pl. Path. 99(1993) Suppl. 3 
where the effect of cropping systems on disease management was studied empirically (Zadoks, 1989). In this experiment, which was started in the Dutch Noordoostpolder in 1979, three farming methods were compared: conventional farming with reliance on high inputs to achieve maximal returns, integrated farming which was aimed at achieving the same financial results as the conventional system, using lower inputs of fertilizers and agrochemicals and reducing spillage in order to save the environment, and an organic farming system which refrained from synthetic fertilizers and pesticides completely on principal grounds. The integrated farming system at the DFS project differed from the conventional system a.o. by using resistant varieties and wide rotations, which reduced soil-borne pest problems and enabled the abolition of soil fumigation. In the integrated system, those varieties of wheat were chosen that we expected to allow control of weeds, insects and pathogens with minimum chemical intervention, accepting a slightly lower maximal yield. Wheat was not sown too early to minimize primary infections with barley yellow dwarf virus. Fertilizer rate and many other long-term decisions were governed by more considerations than just yield maximization. The intuitively risk-averse conventional farming system was risk-seeking in strategic terms because chemical interventions that reduced impact of pests and diseases in the short run, do not prevent the occurrence of problems in the long run. The integrated farming system, which was risk-accepting in tactical terms because chemical pest and disease control was postponed or omitted where possible, was in fact risk-averse from a strategic viewpoint. Rabbinge and Zadoks (1989) demonstrate in their analysis of DFS that strategic decisions, most importantly those concerning crop rotation, can have a much greater impact on pesticide use than tactical and operational decisions during the growing period. A crop rotation in which potato is grown at a frequency of less than once every three years contributes more to pesticide reduction than whatever tactics during the season. Therefore, theoretical and empirical research towards strategic decision-making in pest and disease management requires far more effort than is presently put into it.

\section{Modelling epidemics}

A different purpose requires a different model (Table $i$ ). This seems kicking in an open door, but all too often it is not realized that there is a multitude of valid and useful models

Table 1. Suitability of epidemiological models in relation to objectives of modelling. One plussign indicates suitability for the stated objective, two plus-signs indicate high suitability, a minussign unsuitability.

\begin{tabular}{|c|c|c|c|c|}
\hline \multirow[t]{2}{*}{ Model type } & \multicolumn{4}{|c|}{ Modelling aim } \\
\hline & Exploration & $\begin{array}{l}\text { Mathematical } \\
\text { analysis }\end{array}$ & $\begin{array}{l}\text { Linking } \\
\text { integration } \\
\text { levels }\end{array}$ & Management \\
\hline \multicolumn{5}{|l|}{ Mechanistic / hierarchical / bottom-up } \\
\hline - comprehensive & $+t$ & -1 & ++ & - \\
\hline - summary & + & + & + & + \\
\hline Descriptive / empirical / statistical & - & $\ldots$ & - & $++^{3}$ \\
\hline Analytical / top-down & ++ & ++ & + & - \\
\hline
\end{tabular}

1 Too complex.

2 Trivial.

3 Limited to situations represented in the data used for model calibration. 
for each system. In plant disease epidemiology, temporal, spatio-temporal and spatio-statistical models may be distinguished. Temporal models describe the dynamics of the pathogen population in time, spatio-temporal models describe the dynamics of the pathogen in time and space, while spatio-statistical models describe the spatial extension of disease at a single moment. Spatio-statistical models are often part of spatio-temporal models.

Temporal and spatio-temporal models can be constructed from the top down or from the bottom up. The top-down approach starts with assumedly constant relative growth rate, leading to exponential growth. The next step is consideration of a maximum population level which leads to logistic growth. As a third step, stage structuring of the population is accounted for, resulting in the paralogistic model with classes of healthy, latent, infectious and dead lesions. The exponential model is, despite its simplicity, quite useful in plant disease management. The paralogistic model is an extremely useful tool for analysing the relative importance of components of the life cycle of pathogens.

When the understanding of epidemics under field conditions is the objective, a bottomup approach is appropriate. Here a stage structured pathogen population is the starting point. The population is often divided over leaf layers and possibly also subdivided in the horizontal plane to allow for focal patterns. Models constructed from the bottom up are often rich in descriptive relationships between important process parameters, e.g. spore production rate or infection success, and environmental conditions such as temperature, leaf wetness, or state variables such as leaf age. The strength of thus-constructed hierarchical models is the close tie to the real phenomena in the field. Thus behaviour of the model can be explained in biological terms at the individual level, while gaps in knowledge are identified by the observation that certain parameters cannot be reliably estimated or some processes not described in quantitative terms, or by model rejection at the systems level. Unfortunately, many cases of model rejection do not reach the scientific literature.

The experience is that relationships in hierarchical epidemiological models and the environmental parameters are so poorly known that these models are mostly useless as predictive tools. A potential weakness of complex models is the risk of programming mistakes. One preventive measure against these is good program design, testing of separate modules (Leffelaar, 1993) and publication of full listings of models, as in the former Pudoc Simulation Monograph series. Another safeguard against mistakes is testing the whole or parts of the model for constant conditions for which an analytical solution can be derived. Therefore, the recent development of analytical solutions for the rate of advance of the epidemic wave front and the shape of that front is a major step forward (Van den Bosch et al., 1988a,b, 1989). This is not to say that these analytical models are very practical. They are not because they assume constant dispersal properties of disease and constant spore production rate and infectivity.

For more practical types of analysis in spatial epidemiology, simulation approaches are needed. For instance, Zawolek (1989) uses simulation to investigate the consequences of stochasticity and dual spore dispersal mechanisms on formation of plant disease foci. Earlier on, enlightening simulation studies with a spatial model were conducted by Kampmeijer and Zadoks (1977). The models of Zawolek as well as that of Zadoks and Kampmeijer, can be regarded as spatial extensions of the family of logistic and paralogistic models.

A last example of innovative spatial epidemic modelling in which Zadoks took part is a risk assessment study of Chondrostereum purpureum, silver leaf disease. This fungus has potential as biological control agent against Prumus serotina, an exotic weed tree species in the Netherlands, but is at the same time a pathogen for fruit trees. Risk assessment was based on the Gaussian plume model, which was developed primarily for esti-

Neth. J. Pl. Path. 99(1993) Suppl. 3 
mating spatial transport of air pollution (De Jong, 1988).

There is no single correct way of modelling plant disease epidemics. Each approach, being strictly temporal or spatio-temporal, simulation or mathematical, bottom-up or topdown has strengths and weaknesses and is fit for answering a certain set of questions. The fittest approach to plant disease epidemic modelling will be based on synergism between the different techniques available.

\section{Perspective}

Crop protection is developing more and more towards a technological science based on insight in production-ecological processes at different levels of aggregation. We call this eco-technology. It is no longer a purely empirical science with ad hoc descriptions of elements of pathosystems. Eco-lechnology requires quantitative insight in the spatiotemporal development of plant disease epidemics and a thorough understanding of the nature of damage due to plant diseases. This insight and understanding requires detailed quantitative analyses of pathosystems at the process level as well as at the systems level. Systems approaches have been successful in connecting these levels in the past. This holds mutatis mutandis also for the crop and cropping systems level.

A bright future emerges for systems approaches, as the need for fine-tuning pathosystem management is growing in a world where a productive, competitive and environmentally-sound agriculture is the only sustainable option. Zadoks contributed to the birth, childhood and adolescence of systems approaches in crop protection. He demonstratcd their usefulness in gaining insight and introduced them in pest and disease management. The future will show how mature these approaches are and whether the high expectations of eco-technological approaches, that maximize biological self reliance and minimize negative environmental side-effects of agricultural systems, can be fulfilled. Zadoks may see and watch whether a new generation of quantitative ecological phytopathologists are successful in the use of his heritage.

\section{References}

Carter, N., Dixon, A.F.G. \& Rabbinge, R., 1982. Cereal aphid populations: biology, simulation and prediction. Simulation Monographs, Pudoc, Wageningen. $91 \mathrm{pp}$.

Conway, G.R. (Ed.), 1984. Pest and pathogen control: strategic, tactical and policy models. IIASA, Laxenburg. p. 1-11.

De Jong, M.D., 1988. Risk to fruit trees and native trees due to control of black cherry (Prumus serotina) by silver fungus (Chondrostereum purpureum). PhD. Thesis, Wageningen Agricultural University, the Netherlands. $138 \mathrm{pp}$.

Entwistle, J.C. and Dixon, A.F.G., 1986. Short-term forecasting of peak population density of the grain aphid, Sitobion avenae, on wheat. Annals of Applied Biology 109: 215-222.

Fuchs, A., 1989. The impact of the Department of Phytopathology at the Wageningen Agricultural University, as evaluated by citation analysis. Netherlands Journal of Plant Pathology 95. Supplement 1:215-222.

Hendriks, Th.H.B. \& Van Beek, P., 1991. Optimaliseringstechnieken, principes en toepassingen, derde herziene druk. Bohn, Stafleu, van Loghum, Houten, $348 \mathrm{pp}$.

Kampmeijer, P. \& Zadoks, J.C., 1977. EPIMUL, a simulator of foci and epidemics in mixtures of resistant and susceptible plants, mosaics and multilines. Simulation Monographs, Pudoc. 50 pp.

Kropff, M.J. \& Van Laar, H.H. (Eds), 1993. Modelling crop-weed interactions. CAB-International, Wallingford and International Rice Research Institute, Manila. 274 pp.

Leffelaar, P.A. (ed.), 1993. On system analyses and simulation of ecological processes, with examples in CSMP and FORTRAN. Kluwer Academic Publishers, Dordrecht, 294 pp. 
Mols, P.J.M., 1993. Walking to survive. PhD thesis Wageningen Agricultural University, Wageningen. $203 \mathrm{pp}$.

Netherlands Scietific Council for Government Policy, 1992. Ground for choices; four perspectives for the rural areas in the European Community. SDU Uitgeverij, Den Haag, 144 pp.

Nyrop, J.P. \& Van der Werf, W.. 1993. Sampling to predict or monitor biological control. In: Handbook of sampling methods for arthropods pests in agriculture. In: Pedigo, L.P. \& Buntin, G.D. (Eds): Handbook of sampling methods for anthropods in agriculture, CRC Press, Boca raton, Florida, pp. 247-338.

Rabbinge, R. \& Mantel, W.P., 1981. Monitoring for cereal aphids in winter wheat. Netherlands Journal of Plant Pathology 87: 25-29.

Rabbinge, R. \& De Wit, C.T., 1989. Systems, models and simulation. In: Rabbinge, R., Ward, S.A. \& Van Laar, H.H. (Eds), Simulation and systems management in crop protection. Simulation Monographs, Pudoc, Wageningen. p. 3-15.

Rabbinge R. \& Zadoks, J.C., 1989. Disease and pest control. In: Zadoks, J.C. (Ed.), Development of farming systems, evaluation of the five-year period 1980-1984. Pudoc, Wageningen. p. 32-39.

Rabbinge, R., Ankersmit, G.W. \& Pak, G.A., 1979. Epidemiology and simulation of population development of Sitobion avenae in winter wheat. Netherlands Journal of Plant Pathology 85: 197-220.

Rossing, W.A.H., 1991. Simulation of damage in winter wheat caused by the grain aphid Sitobion avenae. 3. Calculation of damage at various attainable yield levels. Netherlands Journal of Plant Pathology 97: 87-103.

Rossing, W.A.H., Daamen, R.A. \& Hendrix, E.M.T., 1993. A framework to support decisions on chemical pest control under uncertainty, applied to supervised control of aphids and brown rust in winter wheat. Crop Protection, in press.

Van den Berg, H. 1993. Natural control of Helicoverpa armigera in smallholder crops in East Africa. PhD Thesis, Wageningen Agricultural University, the Netherlands, 233 pp.

Van den Bosch, F., Zadoks, J.C. \& Metz, J.A.J., 1988a. Focus expansion in plant disease. I. The constant rate of focus expansion. Phytopathology 78: 54-58.

Van den Bosch, F., Zadoks, J.C. \& Metz, J.A.J., 1988b. Focus expansion in plant disease. II. Realistic parameter-sparse models. Phytopathology 78: 59-64.

Van den Bosch, F., Metz, J.A.J., Frinking, H.D. \& Zadoks, J.C., 1989. Focus expansion in plant disease. III. Realistic parameter-sparse models. Phytopathology 78: 59-64.

Zadoks, J.C., 1971. Systems analysis and the dynamics of epidemics. Phytopathology 61: 600-610.

Zadoks, J.C., 1984. Cost effectiviness of plant protection on a national basis. EPPO Bulletin 14: 325-335.

Zadoks, J.C., 1988. Twenty five years of botanical epidemiology. Philosophical Transactions of the Royal Society, London B 321: 377-387.

Zadoks, J.C. (Ed.), 1989. Development of farming systems. Evaluation of the five-year period 1980-1984. Pudoc, Wageningen. 90 pp.

Zadoks, J.C., 1991. A hundred and more years of plant protection in the Netherlands. Netherlands Journal of Plant Pathology 97: 3-24.

Zadoks, J.C., Chang, T.T. \& Konzak, C.F., 1974. A decimal code for the growth stages of cereals. Weed Research 14: 415-421.

Zadoks, J.C., Rijsdijk, F.H. \& Rabbinge, R., 1984. EPIPRE: A systems approach to supervised control of pests and diseases of wheat in the Netherlands. In: Conway, G.R. (Ed.), Pest and pathogen control. Strategic, tactical and policy models. International Series on Applied Systems Analysis. International Institute for Applied Systems Analysis. p. 344-351.

Zadoks, J.C. \& Schein, R.D., 1979. Epidemiology and plant disease management. Oxford University Press, New York. 427 pp.

Zawolek, M.W., 1989. A physical theory of focus development in plant disease. PhD Thesis, Wagcningen Agricultural University, Wageningen. $230 \mathrm{pp}$. 